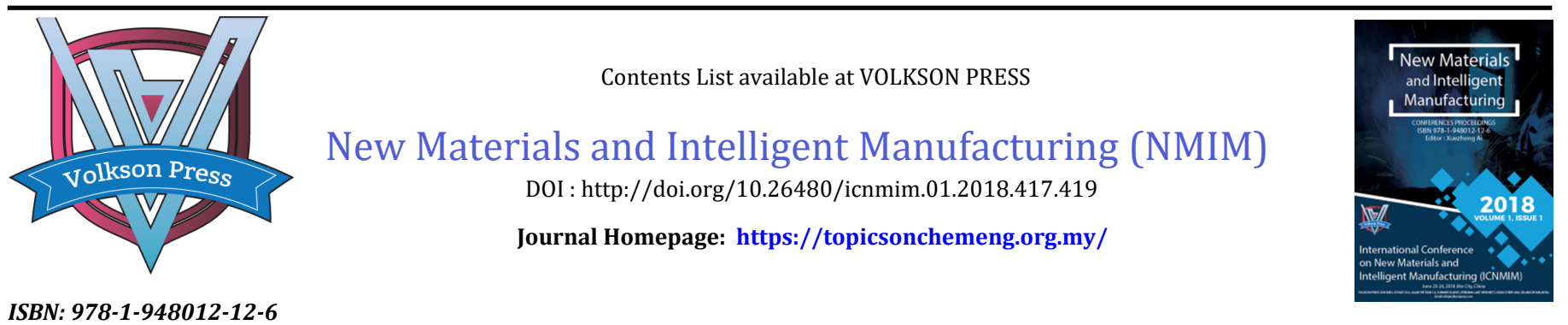

ISBN: 978-1-948012-12-6

\title{
PURIFICATION OF ANTHOCYANINS FROM FRUIT OF ARONI AMELANOCARPA
}

\author{
Song Jiangang, Zhong Fangli*, Wang Xiaolin and Feng Yangyang \\ School of Chemistry and Pharmaceutical Engineering, Jilin Institute of Chemical Technology, Chengde Street, Jilin, China \\ *Corresponding Author E-mail: fanglizhong@sina.com
}

This is an open access article distributed under the Creative Commons Attribution License, which permits unrestricted use, distribution, and reproduction in any medium, provided the original work is properly cited

\section{ARTICLE DETAILS}

\section{Article History:}

Received 26 June 2018

Accepted 2 July 2018

Available online 1 August 2018

\section{ABSTRACT}

Five different macroporous resins were evaluated for the adsorption properties of the anthocyanins extracted from the Aroni amelanocarpa fruit. The effects of initial anthocyanin concentration, amount of elution solvent, elution velocity and ethanol concentration were studied by the dynamic adsorption/desorption method. Results showed LSA-10 possessed the best purification capability. The optimum adsorption conditions were $120 \mathrm{~mL}$ of 55.77 $\mu \mathrm{g} / \mathrm{mL}$ sample, $1.5 \mathrm{~mL} / \mathrm{min}$ of flow rate. The elution solvent was $120 \mathrm{~mL}$ of $50 \%$ ethanol at velocity of $1.5 \mathrm{~mL} / \mathrm{min}$. After being processed by LSA-10, the purity of anthocyanin in the crude extracts increased from $0.24 \%$ to $1.96 \%$.

\section{KEYWORDS}

Aronia melanocarpa, Anthocyanin, Macroporous adsorption resin, Purification.

\section{INTRODUCTION}

Aroni amelanocarpais belongs to the Rosaceae family. Based on a study, it is rich in nutrition components such as anthocyanins, polyphenols, flavonoids and other functional ingredients, which possess antiinflammatory, anti-radiation, hypoglycemic, liver protection [1-4]. Therefore, development and utilization of its functional components is extremely important.

According to research, macroporous resin is a separation material with adsorption and selectivity [5]. It has been widely used in extraction, separation, and purification of active ingredients in Chinese herbal medicines due to the advantages of ideal adsorption, selectivity, large processing capacity, mild desorption conditions and low cost $[6,7]$. However, study on purification of anthocyanin from the fruit of aroni amelanocarpa is rarely reported until now. Therefore, in this study, five kinds of macroporous adsorptive resins were investigated for purifying anthocyanins anthocyanins, the resins were screened by static adsorption/desorption method, and the purification process was performed in a dynamic adsorption. The present study can provide scientific basis for the rational development, utilization, separation and purification of anthocyanins resource in fruit of aroni amelanocarpa.

\section{MATERIALS AND METHODS}

\subsection{Materials and Equipment}

\subsubsection{Materials and Reagents}

Aroni amelanocarpa fruit was purchased from Jilin province aroni amelanocarpa fruit agricultural science and technology development limited liability company. Standards of Cyanidin was purchased from Chengdu Manste Biotechnology Co., Ltd. Macroporous resin (LSA-21、 LSA-10、AB-8 、 LX-36、D-101) were purchased from Xi'an Lanxiao Technology Co., Ltd. The rest of the reagents were of analytical grade.

\subsubsection{Instruments and Equipment}

TU-1810 UV-Visible Spectrophotometer (Beijing Genesis General Instrument Co., Ltd.). RE-52AA Rotary Evaporator (Shanghai Arong
Biochemical Instrument Co., Ltd.). SHA-B water bath thermostatic oscillator (Jintan Branch). FD5-2.5 Laboratory Freeze Dryer (Shanghai Huifen Electronic Technology Co., Ltd.).

\subsection{Determination of anthocyanin content}

Standard stock solutions of cyanidin $(54 \mu \mathrm{g} / \mathrm{mL})$ was prepared by dissolving them in $0.1 \mathrm{M}$ citric acid. According to a study, they were then serially diluted for preparation of standard solutions according to the UVvisible spectrophotometric method [8]. Good linearity $\left(\mathrm{r}^{2}>0.9996\right)$ of cyanidin was observed in calibration curves over the concentration ranges $(2.7 \sim 18.9 \mu \mathrm{g} / \mathrm{mL})$.

\subsection{Preparation of anthocyanin sample}

Dry aroni amelanocarpa fruit was extracted at $90{ }^{\circ} \mathrm{C}$ in a water bath for 1.5 h. The extracts were filtered through a filter paper and then diluted to certain concentration for use.

\subsection{Purification Process of Anthocyanin}

\subsubsection{Pretreatment of Macroporous Resins}

Five kinds of resin LX-36, AB-8, LSA-21, LSA-10 and D-101 were leached with $95 \%$ ethanol for $2 \mathrm{~h}$ and washed several times with deionized water. Subsequently, the resins were soaked in $5 \%$ hydrochloric acid for $4 \mathrm{~h}$ and then washed by distilled water. The washed resins were soaked in $2 \%$ $\mathrm{NaOH}$ solution for $6 \mathrm{~h}$. Finally, the resins were washed by distilled water thoroughly [1-4].

\subsubsection{Selection of Macroporous Resins}

The preselection of resins was evaluated by their adsorption capacities and desorption ratios. $4.0 \mathrm{~g}$ of the five kinds of pretreated resins and 60 $\mathrm{mL}$ of $49.92 \mu \mathrm{g} / \mathrm{mL}$ sample mentioned-above were added into a stoppered flask. The flasks were shaken on a shaker at $27^{\circ} \mathrm{C}$ for $24 \mathrm{~h}$. The solution after adsorption was analyzed using the UV-vis spectrophotometer. Desorption experiments were conducted as follows: after the attainment of adsorption equilibrium, the absorbed resins were filtered and then added with $100 \mathrm{~mL}$ of $80 \%$ ethanol solution with a lid. The flasks were 
shaken on a shaker at $27^{\circ} \mathrm{C}$ for $24 \mathrm{~h}$. The adsorption rate and desorption rate of five resin was calculated using the following equation:

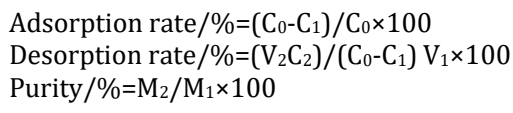

Where $\mathrm{C}_{0}, \mathrm{C}_{1}$ and $\mathrm{C}_{2}$ were mass concentrations $(\mu \mathrm{g} / \mathrm{mL})$ of anthocyanin in extract solutions, after adsorption and desorption, respectively. $\mathrm{V}_{1}$ and $\mathrm{V}_{2}$ were the volume $(\mathrm{mL})$ of sample and desorption solution solution. $\mathrm{M}_{1}$ and $\mathrm{M}_{2}$ were dry solid mass (mg) and anthocyanin calculation mass of desorption solution, respectively.

\subsubsection{Dynamic adsorption and elution experiments.}

LSA-10 macroporous adsorption resin was packed into a glass column. A certain volume of sample with different concentrations (12.01, 27.93, $44.04,55.77$ and $66.79 \mu \mathrm{g} / \mathrm{mL}$ ) of anthocyanins was introduced downward into the column at flow velocity of 1.0, 1.5, 2.0, 2.5, and 3.0 $\mathrm{mL} / \mathrm{min}$. The concentration of anthocyanins in the exit solution was analyzed by the UV-vis spectrophotometer. After the adsorption equilibrium was reached, the column was sequentially eluted with certain amount of ethanol aqueous $(10 \%, 30 \%, 50 \%$ and $70 \%)$ at different flow velocity $(1.0,1.5,2.0,2.5$ and $3.0 \mathrm{~mL} / \mathrm{min})$. The concentration of anthocyanins in the desorption solution was analyzed by the UV-vis spectrophotometer.

Breakthrough adsorption capacity and saturation capacity were calculated on the basis of the number of anthocyanins adsorbed when the concentration of the exit from the column reached $5 \%$ and $95 \%$ of the inlet

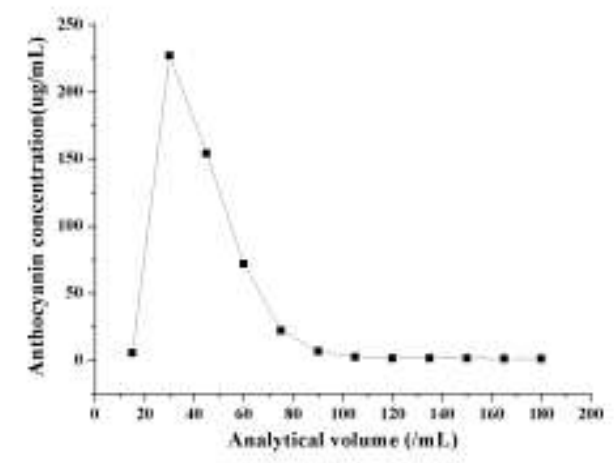

Figure 1: The curves of leakage

\subsubsection{Effect of sample concentration on adsorption rate}

As shown in Table 2, the resin exhibited the highest adsorption rate when sample was $55.77 \mu \mathrm{g} / \mathrm{mL}$. The reason may be certain increase of sample solution concentration, respectively.

\section{RESULTS AND ANALYSIS}

\subsection{Selection of macroporous adsorption resins}

The static adsorption and desorption rates of anthocyanin for five resins were shown in Table 1. It was clear LSA-10 possessed the optimal adsorption/desorption capacity rate for anthocyanins. Hence, LSA-10 was applied for the following study.

Table 1: Adsorption and analytical properties of macroporous resin

\begin{tabular}{cccc}
\hline Types & LSA-10 & LSA-21 & AB-8 \\
\hline $\mathrm{A}_{1}$ & 0.059 & 0.038 & 0.085 \\
$\mathrm{~A}_{2}$ & 0.381 & 0.352 & 0.357 \\
$\mathrm{C}_{1} /(\mu \mathrm{g} / \mathrm{mL})$ & 5.39 & 3.61 & 7.60 \\
$\mathrm{C}_{2} /(\mu \mathrm{g} / \mathrm{mL})$ & 19.62 & 18.15 & 18.40 \\
Adsorption rate $(/ \%)$ & 89.19 & 92.76 & 84.78 \\
Desorption rate $(/ \%)$ & 73.45 & 66.66 & 73.76 \\
\hline
\end{tabular}

\subsection{Single factor test}

\subsubsection{Effect of sample volume on adsorption rate}

As can be seen from the Fig. 1, when the volume of sample was $120 \mathrm{~mL}$ the porous structure of macroporous resin reached saturation and the adsorption rate reached the highest. Therefore, the optimal sample volume was selected to be $120 \mathrm{~mL}$.



Figure 2: Ethanol elution volume on adsorption rate

concentration increased the contact area between resin and adsorbed material. Therefore, the suitable sample concentration was determined to be $55.77 \mu \mathrm{g} / \mathrm{mL}$.

Table 2: The investigation results of the concentration of the upper sample

\begin{tabular}{llllll}
\hline Concentration $(\mu \mathrm{g} / \mathrm{mL})$ & 12.01 & 27.93 & 44.04 & 55.77 & 66.79 \\
\hline $\mathrm{A}_{1}$ & 0.029 & 0.043 & 0.042 & 0.086 & 0.120 \\
$\mathrm{C}_{1} /(\mu \mathrm{g} / \mathrm{mL})$ & 1.71 & 2.42 & 2.37 & 3.37 & 6.34 \\
Adsorption rate(/\%) & 85.76 & 91.33 & 91.51 & 93.96 & 90.51 \\
\hline
\end{tabular}

\subsubsection{Effect of flow rate on adsorption rate}

The experimental results show that the adsorption rate increased first and then decreased with the increase of adsorption velocity. Furthermore, the adsorption rate reached the highest when the flow rate was $1.5 \mathrm{~mL} / \mathrm{min}$. Therefore, $1.5 \mathrm{~mL} / \mathrm{min}$ was selected.

Table 3: Investigation results of adsorption velocity

\begin{tabular}{llllll}
\hline Velocity of flow $(\mu \mathrm{g} / \mathrm{mL})$ & 1.0 & 1.5 & 2.0 & 2.5 & 3.0 \\
\hline $\mathrm{A}_{1}$ & 0.020 & 0.016 & 0.039 & 0.050 & 0.069 \\
$\mathrm{C}_{1} /(\mu \mathrm{g} / \mathrm{mL})$ & 1.25 & 1.05 & 2.22 & 2.78 & 3.75 \\
Adsorption rate $(/ \%)$ & 97.49 & 97.90 & 95.56 & 94.43 & 92.49 \\
\hline
\end{tabular}

\subsubsection{Effect of eluent on desorption rate}

As shown in Table 4, the desorption rate reached the highest and the elution effect performed the best when ethanol concentration was 50 with the increase of ethanol concentration. Therefore, $50 \%$ ethanol was used as eluent. 
Table 4: Investigation result of elution solvent

\begin{tabular}{llllll}
\hline Eluent & $\mathrm{H}_{2} \mathrm{O}$ & $10 \%$ & $30 \%$ & $50 \%$ & $70 \%$ \\
\hline $\mathrm{A}_{1}$ & 0.027 & 0.035 & 0.042 & 0.038 & 0.066 \\
$\mathrm{C}_{1} /(\mu \mathrm{g} / \mathrm{mL})$ & 2.88 & 2.02 & 2.32 & 9.17 & 3.59 \\
Adsorption rate(\%) & 94.67 & 96.27 & 95.70 & 95.98 & 93.35 \\
$\mathrm{~A}_{2}$ & 0.027 & 0.245 & 0.799 & 74.00 & 0.544 \\
$\mathrm{C}_{2} /(\mu \mathrm{g} / \mathrm{mL})$ & 1.61 & 21.17 & 68.16 & 95.18 & 69.80 \\
Desorption rate(\%) & 2.09 & 27.15 & 87.93 & 95.32 \\
\hline
\end{tabular}

\subsubsection{Effect of elution flow rate on desorption rate}

The data of elution flow rate was shown in Table 5. With the increase of elution flow rate, desorption rate rises firstly and then decreased. The desorption rate reached the highest when the elution flow rate was 1.5 $\mathrm{mL} / \mathrm{min}$. Hence, $1.5 \mathrm{~mL} / \mathrm{min}$ was adopted.

Table 5: Investigation results of elution flow velocity

\begin{tabular}{|c|c|c|c|c|c|}
\hline Elution flow rate $(\mathrm{mg} / \mathrm{mL})$ & 1.0 & 1.5 & 2.0 & 2.5 & 3.0 \\
\hline $\mathrm{A}_{1}$ & 0.036 & 0.040 & 0.037 & 0.048 & 0.065 \\
\hline $\mathrm{C}_{1} /(\mu \mathrm{g} / \mathrm{mL})$ & 2.07 & 2.27 & 2.12 & 2.68 & 3.54 \\
\hline Adsorption rate $(\%)$ & 96.17 & 95.79 & 96.08 & 95.04 & 93.44 \\
\hline $\mathrm{A}_{2}$ & 0.546 & 0.577 & 0.497 & 0.482 & 0.477 \\
\hline $\mathrm{C}_{2} /(\mu \mathrm{g} / \mathrm{mL})$ & 70.05 & 73.99 & 63.82 & 61.91 & 61.27 \\
\hline Desorption rate(\%) & 89.90 & 95.36 & 82.90 & 80.41 & 80.03 \\
\hline
\end{tabular}

\subsubsection{Effect of amount of eluent on desorption rate}

As shown in Figure 2, the concentration of anthocyanin in the effluent increased firstly and then decreased following with the increase of eluent amount. There was almost no change in the anthocyanins mass concentration when the eluent volume was $120 \mathrm{~mL}$. Therefore, the optimal volume of eluate was determined to be $120 \mathrm{~mL}$.

\subsection{Process verification test}

In order to study the stability of the process, three independent samples in parallel were subjected to the above preparation and analysis. Results showed the adsorption rates were $97.90 \%, 97.75 \%$ and $98.23 \%$, respectively. Average adsorption rate was $97.96 \%$. The desorption rate was $94.18 \%, 89.28 \%$ and $89.82 \%$, respectively, average desorption rate was $91.09 \%$. Therefore, the experimental procedures showed a good reproducibility.

\subsection{Determination of anthocyanins content in samples}

The sample was analyzed in triplicate to determine the content. Results showed the average purity of anthocyanin increased from $0.24 \%$ to $1.96 \%$ after treated by resin indicating LSA-10 could purify anthocyanins in the aroni amelanocarpa fruit significantly.

\section{CONCLUSION}

In the present study, the separation characteristics of five kinds of macroporous resins were systematically investigated. LSA-10 exhibited ideal purification efficiency of anthocyanins from the aroni amelanocarpa fruit extracts than the other four adsorbents. The optimal adsorption conditions were $120 \mathrm{~mL}$ of $55.77 \mu \mathrm{g} / \mathrm{mL}$ sample solution, $1.5 \mathrm{~mL} / \mathrm{min}$ of velocity. The elution conditions were $120 \mathrm{~mL}$ of $50 \%$ ethanol at the velocity of $1.5 \mathrm{~mL} / \mathrm{min}$. Under the optimal conditions, the purity of anthocyanin in the crude extracts increased from $0.24 \%$ to $1.96 \%$. which indicated that LSA-10 macroporous adsorption resin could purify the anthocyanin from the aroni amelanocarpa fruit. This study provided a theoretical basis for the large-scale production of anthocyanins from aroni amelanocarpa fruit in industry.

\section{REFERENCES}

[1] Zhu, Y., Li, F.M., Wang, Y.L., Zhu, N., Zhang, H.P., An, J.H., Sun, A.D. 2017. Extraction and antibacterial properties of proanthocyanidins from the black fruit rib pods. Science and Technology of Food Industry, 38 (2), 302$306+341$.

[2] Sun, Z.M., Zhang, J.L., Zhou, X. 2017. Research Progress on the Antioxidant Effect of Polyphenols in the Bark of Ulva striata. Science and Technology of Food Industry, 38 (9), 396-400.

[3] Chen, S.S., Meng, X.J., Wang, Y.H., Sun, X.Y. 2018. Antioxidant Activity and Optimisation Of Ultra Sonic-Assisted Extraction by Response Surface Methodology of Aronia Melanocarpa Anthocyanins. Matrix Science Pharma, 2 (1), 06-09.

[4] Yu, X., Hu, W.Z., Jiang, A.L., Chen, Y.Z., Liu, X.B. 2016. Research progress on nutrient substances and efficacy of the black fruit ovary. Science and Technology of Food Industry, 37 (10), 396-400.

[5] Zhang, Z.P., Zhao, L.P., Nie, W.J., Wang, D.P., Jiang, Y. 2012. Study on Separation and Purification of Mulberry Anthocyanins from AB-8 Macroporous Resin. China Food Industry, 33 (9), 43-45.

[6] Wang, X.L., Jin, L.Z., Zhong, F.L., Yu, S. 2018. Study on purification process and antioxidation of total flavonoids from cinnamon. China Food Additives, (1), 119-127

[7] Xiang, X., Sun, C.J., Su, S.L., Gu, J.F., Guo, S., Shang, E.X., Yan, H., Qian, D.Z., Duan, J.B. 2018. Study on the extraction and purification process of effective fraction of phenolic ketone from stem and leaf of Salvia miltiorrhiza Bunge. Chinese Traditional and Herbal Drugs, 49 (1), 120 127.

[8] Li, R.F. 2017. Ultrasonic-assisted extraction of flavonoids from the scopolamine of the black fruit gland and its anti-fatigue effect. Food Research and Development, 38 (13), 63-68. 